material, and the same process is being studied for possible use with artificially induced, short-lived radioactivity (gamma-radiation) for a selected mineral such as one containing beryllium.

Another incipient aid to fundamental work promises to be the differentiation between slightly varying crystals of what are loosely grouped as the same mineral. For example, galena (lead sulphide) could be thought of as being just galena; but minute traces of impurity and minute variations in its lattice structure and discontinuity make profound differences in its behaviour, both in study and in its practical concentration from its ores. These differences can be greatly magnified by the use of suitable radioactivating techniques.

The Lecture provided an admirable introduction to the symposium held at the Imperial College of Science and Technology, London, by the Institution of Mining and Metallurgy during the following three days, when about forty papers were presented and at which a wide variety of research and practical aspects of this important and growing technology was examined. In recognition of his distinguished services, honorary membership of the Institution of Mining and Metallurgy was conferred on Prof. Gaudin before he gave the Lecture.

\section{RESEARCH COUNCIL OF ALBERTA REPORT FOR 1951}

$\mathrm{T}$ HE thirty-second annual report of the Research Council of Alberta*, describing the work of the Council in 1951, again stresses the work on the bituminous oil sands; and preparation for the Athabasca Oil Sands Conference, which was sponsored by the board of trustees of the Oil Sands Project, made heavy demands on the Research Council's staff. The terms 'bituminous sand' and 'tar sand' have now been dropped, because of their false implication, in favour of 'oil sands'. Laboratory investigations have confirmed the presence of vanadium in the oil sand, both as a mineral and as a component of the oil, especially in the resin and asphaltene fractions. Some work was done on the characteristics of the flow of sand suspensions, including a study of the friction factor in pipes, as well as on the electrical resistance of oil sand and its breakdown under a high potential difference.

A balanced programme of studies on coal included a study of the absorption spectra of oxidation degradation products of Alberta sub-bituminous coals in aqueous solution, of the cleaning of coal with cyclone washer equipment, analytical and physical testing, and of the physical properties of magnetite, Burmis iron ore, loess, limestone and tailings from a zinc refinery with reference to their suitability for the preparation of the media used in dense-media processes of cleaning coal.

A reconnaissance pleistocene survey was made of the Lake St. Ann map area, and the Gasoline and Oil Testing Laboratory again surveyed gasolines sold in the area and initiated a study of viscosity data at low temperatures on aviation lubricating oils diluted with aviation fuel, and one on the effect of storage time on preformed gum, and on 5-hr. and 16-hr. potential gum tests on aviation fuel. The pyrolysis of natural gas, the partial oxidation of butane, and * Thirty-second Annual Report of the Research Council of Alberta,
1951. Pp. 32. (Edmonton : Queen's Printer, 1952.) the National Research Council's Pidgeon process for carbon black received attention, while irrigation soilsurvey work on the Bow River project was started and the William Pearce project was continued. A re-survey of the Edmonton map sheet was commenced, and work on the Sturgeon Lake sheet resumed. The investigation of biological cycles continued, particularly with reference to the fluctuations of wild life in northern latitudes, and measurement of ultra-violet solar radiation continued with the thorium photo-cell and with a zirconium photocell in spite of adverse conditions. A list of publications of the Council is appended.

\section{A WAVE-RECORDER FOR USE IN SHIPS}

\section{BY M. J. TUCKER}

National Institute of Oceanography

A LTHOUGH sea-waves have been recorded for a A number of years using shore-connected pressuremeasuring instruments or inverted echo-sounders laid on the sea-bed, collection of exact information about waves, studies of the growth of waves relative to the wind, and studies of ship motion and of coastal changes relative to the waves have always been retarded by the absence of a reliable method of continuously recording waves from a ship in deep water.

Some measurements have been made by a method in which an observer stations himself at such a height that the top of a wave comes just level with the horizon when the ship is on a fairly even keel in the trough. Much more accurate measurements have been made by stereo-photogrammetric methods using cameras with a long base-length mounted high on the ship.

Neither of these methods is satisfactory for obtaining a continuous picture of changing wave conditions, and for this purpose the best method until recently has been that employed before the Second World War by the Deutsche Versuchanstalt für Luftfahrt for the study of seaplane landings in a variety of wave conditions. In this method a pressure recorder was suspended on a steel wire $100-200 \mathrm{ft}$. below a flat lens-shaped float : because of the rapid attenuation of wave-pressure with depth, the recorded pressure fluctuations were mainly due to the recorder following the vertical movements of the float on the surface. A correction could be made for the residual wave motion at the depth of the recorder when the presence of long waves made this necessary. The pressure fluctuations were recorded by a diaphragm connected to a diamond which scratched a spiral record on a polished steel cylinder rotated and moved along its axis by clockwork. The scratch recorder has been replaced in Great Britain by an electrical pressure recorder the output of which is transmitted to the attendant ship by wireless or by a buoyant cable, but the basic idea is the same. Measurements have also been made by an apparatus attributed to Froude and which consists of a buoyant graduated pole held vertical by a weight on its lower end and kept steady in the water by a drogue of relatively large area suspended on $200 \mathrm{ft}$. of wire from the bottom of the pole. The movements of the water up and down the pole are usually observed visually or photographed, but on a recent voyage of the R.R.S. 